\title{
Differences in Learning Outcomes and Engagement Across Traditional, Blended, and Online Engineering Management Undergraduate Courses
}

\section{Dr. Ulises Daniel Techera, University of Colorado, Boulder}

Ulises D. Techera recently graduated with a Ph.D. in Civil Engineering from the University of Colorado at Boulder. His research interests include construction management and safety, and education in engineering. Dr. Techera also graduated with a BS in Civil Engineering and an MS in Structural Engineering from the Polytechnic University of Catalonia in Barcelona. Ulises has worked in the construction industry for 4 years and in academia for 3 years.

\section{Dr. Christy Bozic, University of Colorado, Boulder}

Christy Bozic Is the Stephen M. Dunn Professor of Engineering Management and Faculty Director of the Undergraduate Program at the University of Colorado Boulder. She holds a Ph.D. in Curriculum and Instruction, an M.B.A. in Marketing, and a Bachelors degree in Industrial Engineering Technology. Dr. Bozic builds upon her extensive industry experience to develop undergraduate curriculum to better prepare undergraduate engineers for careers in business and engineering management.

\section{Seth Murray, University of Colorado, Boulder}

Seth is an engineer and entrepreneur. He specializes in small business development, mechanical design and manufacturing, marketing, and finance. He has founded and run two successful companies. His experiences include iPhone apps, medical devices, baby carriers, mobile advertising, flow meters, and climbing equipment. He received a bachelor's degree from $\mathrm{CU}$ in mechanical engineering and a master's in engineering management. 


\title{
Differences in Learning Outcomes and Engagement Across Traditional, Blended, and Online Engineering Management Undergraduate Courses
}

\begin{abstract}
Traditionally, Engineering Management (EM) courses have formed part of graduate programs. These courses usually included some type of asynchronous learning delivery system to give more flexibility to the students who had a full-time job and family commitments. The relevance of acquiring business and social skills to succeed in the industry has become evident. Thus, an increasing number of universities have incorporated EM courses into the undergraduate curriculum with many offering minors in EM. The new EM courses at the undergraduate level carried with them asynchronous learning characteristics that allow for distance learning and online interaction giving students more flexibility compared to traditional synchronous courses. Through this research, the differences in learning outcomes and engagement across four different types of undergraduate students belonging to a traditional, a blended, or an online EM course, have been studied for the first time. These differences were analyzed for a quantitative course and a qualitative course across five consecutive terms. A total of 390 students from the University of Colorado-Boulder participated in the study. The results indicate that learning outcomes, such as homework and tests grades, improved when transitioning from a traditional course to a blended course to an online course. However, when comparing face-to-face and distance students within blended courses, distance students showed to have a lower learning quality experience than faceto-face students. The results of this study can aid institutions in making decisions regarding course modality implementation.
\end{abstract}

Introduction

Engineering Management (EM) degrees and programs emerged at the higher education level to fulfill the need for instruction in the competencies engineers need to be successful in the industry. The practice of engineering requires more than the technical knowledge of the engineering processes; it requires business and social skills which are not expressly taught within traditional engineering courses. Consequently, most attendants to EM graduate programs were full-time working engineers who needed these skills to progress in their companies. The busy schedules of these students have shaped the way in which EM courses have been taught. From the beginning, these courses have used asynchronous instructional methods such as recorded classes, which were made available to the students to view and study at their convenience. This modality is called "blended" because it allows students to receive instruction face-to-face or through the recording of the lecture. More recently, the "online" modality has been implemented, in which students receive instruction online, but not necessarily recorded in a classroom setting.

Throughout the years, the business and social skills taught in EM have gained importance, to the point where programs greatly proliferated at the graduate level and more recently at the undergraduate level. In 1967, the University of Missouri-Rolla developed the first EM academic department (Murray \& Raper, 1997). There are currently only nine states that don't offer a graduate program (ASEM, 2017). Compared to graduate programs, there are fewer undergraduate EM degrees and programs (Kotnour \& Farr, 2005). Undergraduate programs present a different demographic characterized by younger students who, for the most part, do not have a full-time job 
or significant family commitments. Consequently, these students can devote more time to attend classes when compared to graduate students. For this reason, undergraduate EM education has primarily consisted of classroom courses where students are taught in the traditional lecture modality like other undergraduate courses. Nonetheless, the advantages of asynchronous courses such as: student-focused instructional methods, greater flexibility, and lower implementation costs have given place to the incorporation of asynchronous curriculum delivery at the undergrad level.

The impact on learning outcomes of the implementation of asynchronous courses in undergraduate EM programs has not been previously studied. The researchers addressed this gap in knowledge. Differences in grades and engagement among four different types of students, as characterized by the way in which they participated in the course, were assessed. Students that participated in a "traditional classroom" undergraduate EM course will be referred to as "Traditional" students. Students that interacted face-to-face with the instructor but were enrolled in a blended learning course will be referred to as "Face-to-Face" students. Students who watched the recorded classes in a blended course will be identified as "Distance" students. It is important to mention that these last two types of students ("Face-to-Face" and "Distance") attended the same blended style course that offered those two types of interactions. The instructor teaches students in the classroom while the lesson is recorded and uploaded to the learning management system for the distance students to view later. Lastly, students who received instruction from prerecorded videos in which the instructor addresses the students directly in a virtual one-on-one teaching style outside the classroom will be recognized as "Online" students. Table 1 summarizes the types of students and the corresponding course modality.

Table 1: Student Types

\begin{tabular}{ll}
\hline Course Modality & Type of Students \\
\hline Traditional & Traditional \\
\hline Blended & Face-to-Face \\
& Distance \\
\hline Online & Online \\
\hline
\end{tabular}

Given these four types of students, three major research questions were generated: (1) Is there a difference in students' learning outcomes across student types? (2) Is there a difference in students' engagement across these student types? (3) Do the results vary between students of different courses? To answer these questions, the present study analyzed data obtained from 390 undergraduate students who attended an undergraduate EM course at the University of ColoradoBoulder, as one of the aforementioned types of students. The results obtained from this analysis will also allow us to derive conclusions regarding the effectiveness of the three different course modalities.

Literature review

\section{Learning outcomes}

According to the National Committee of Inquiry into Higher Education, one of the most desirable learning outcomes in Higher Education is to produce autonomous learners (Dearing, 1997). As 
understood by Crome et al, Autonomous Learning is "the ability to think and act critically and independently, to self-manage study and learning, and realistically to appraise one's strengths and weaknesses as a learner" (Crome, Farrar, \& O'Connor, 2009, p. 114). To prepare students to succeed in the current professional world, it is vital to help them become autonomous learners (Dearing, 1997). The recent explosion of technology has greatly contributed to the globalization of markets, education, and societies which give place to a massive flow of information and the rapid creation of new knowledge. This generates new careers and occupations that require continuous learning and specialization (Candy, Creber, \& O'leary, 1994).

Several researchers agree that engagement, interaction, reflection, analysis, and discussion foster autonomous learning (Barr \& Tagg, 1995; Little, 1996; Weimer, 2002). Kuh et al. (2009) define engagement in education as the individual effort to participate in educational activities inside or outside the classroom. The level of engagement of a student will depend on two main factors: (1) the time and energy invested by the student participating in educational activities; and (2) the resources deployed by the educational institution to provide learning opportunities (Kuh et al. 2011, p. 44). Previous studies show the more engaged students are, the more they learn (Astin, 1984; Carini, Kuh, \& Klein, 2006; Cross, 1999). Furthermore, engagement is also positively correlated to grades (Handelsman, Briggs, Sullivan, \& Towler, 2005).

Interaction between students and the instructor has been recognized as an essential component for engagement and learning (Astin, 1984; Ewell \& Jones, 1996; Fries-Britt, 2000; Schwitzer \& Lovell, 1999). Additionally, students that actively interact with professors and other students manifest higher self-efficacy and overall satisfaction with the course (Maeroff , 2003; Schwitzer \& Lovell, 1999).

The development of new instructional methods for undergraduate EM courses allows for new ways of engagement, interaction, reflection, analysis, and discussion, making imperative the assessment of student's learning outcomes among these different methods. The following sections offer a brief review of the advantages and disadvantages of each of the three course modalities addressed in this study.

\section{Traditional courses}

Perhaps the most criticized aspect of a traditional teaching style is that it encourages passive learning. In other words, learning objectives are digested by the instructor and then presented to the students in a lecture format inhibiting a self-pace development of knowledge by the student. Traditional lecture instructional methods have been criticized as not encouraging the development of higher-order thinking skills that require more time and reflection than available in this type of course (Banathy, 1994; Hannum \& Briggs, 1982). Additionally, traditional lecture courses require a higher investment of time and resources from the students, professors, and the institution (Leasure, Davis, \& Thievon, 2000; Oliver \& Omari, 2001). On the other hand, some authors agree that traditional learning offers a higher quality of human interaction unmatched by other course modalities (Meyer-Peyton, 1999; Purcell-Robertson \& Purcell Sr, 1999). 


\section{Online courses}

As defined by Johnson et al. (2000) "Online instruction is a form of distance education delivered over the Internet." For many, this type of instruction represents a revolutionary advancement in education because it allows for instruction to numerous populations traditionally left out from university due to the lack of flexibility and access to traditional education. Online learning often reaches those who have busy schedules or who live in remote areas which make it difficult to attend university classes in person (Hill, 1997; Webster \& Hackley, 1997).

Among the most relevant advantages of online courses is the fact that they are student-oriented (Edwards, Cordray, \&Dorbolo, 2000; Maeroff, 2003). The student has the ability and personal responsibility to choose when to take and how to contribute to the class, making the student more involved in the learning process. Additionally, online courses rely on online tools such as threaded discussions and blogs which have shown to increase interaction between peers and between students and professors (Rabe-Hemp, Woollen, \& Humiston, 2010). In traditional courses, the time for interaction is limited to the duration of the class. On the other hand, threaded discussions and blogs allow for a continuous open line of interaction. The students and the professors have more time to think and review their contributions. Consequently, online education has also shown to produce higher and more critical levels of thinking when compared to traditional courses (Newman, Webb, \& Cochrane, 1995). The increased amount of time pondering learning objectives to write a paragraph that will be read by peers and professors has also shown to increase the perception of learning among students (Meyer, 2003).

Another advantage of online learning is the immediate interaction available through online tools. This has generated both a greater satisfaction with the course and sense of proximity to peers and professors (Collins, 2000; Fredericksen, Pickett, \& Shea, 2000). In addition, Rabe-Hemp et al. (2010) suggest professors may enjoy a reduction in class preparation time. While it is true that the first time a professor teaches an online course, it requires copious amounts of time to produce the learning materials for the course. After that first year, the professor can often reuse those materials and make small adjustments, thus saving a significant amount of time.

These perspectives of online education are widely challenged by others who claim exactly opposite results. Several authors have identified feelings of isolation, lower interaction, and lower course satisfaction among online learners (Brown, 2001; Fishman, 1999; Kulik \& Kulik, 1991). Additionally, online learning lacks non-verbal communication that not only enriches the conversation, but at times it communicates more than the words themselves (Meyer, 2003).

Another challenge for online students is the responsibility to decide where and when to access the class material. While this can be seen as an advantage due to the greater flexibility; it also represents a challenge to prioritize organization (Bullen, 2007). Along those lines, finding the right time to work in groups is another challenge for online students who don't have the need to be at the same place at a given time on a regular basis (Santiago \& Abioye, 2014).

Given the tradeoffs of online learning, many educators have promoted a blended learning style that combines traditional with online learning (Reay, 2001). The advantages and disadvantages of this course modality are addressed in the following section. 


\section{Blended courses}

Blended courses claim to offer the best of online and traditional learning systems (Lamport \& Hill, 2012). There are different modalities of blended courses. For example, some blended courses reduce the amount of face-to-face instruction in exchange for online instruction. This can be accomplished by substituting some traditional classes during the week for online classes. Another way of combining these two course modalities is by providing traditional classes at the beginning and end of the term and online classes in between. Several universities implemented these approaches and noticed a remarkable increase in Return on Investment (ROI) (Karabulut-Ilgu \& Jahren, 2016). Other blended courses don't reduce the amount of time spent in the traditional classroom, instead, they add technology to the classroom and rely on online tools that allow for real-time interaction with distance students. These blended courses also offer video recordings of each class for those who can't attend class in person or online in real time.

According to a meta-analysis carried out by the U.S. Department of Education, blended courses offer learning tools not found in traditional or online courses. As a result, students invest more time and effort in this type of course, thus producing better learning outcomes. This same study concluded that online courses produce better learning outcomes than traditional courses (Means, 2009).

This study represents a unique effort to assess the influence of different course modalities in learning outcomes among undergraduate students who attended EM courses. The results of this study will help to the organization of future courses. The following section explains the protocol followed to answer the research questions.

Methodology

The overall protocol of this study consisted in comparing learning outcomes between the four types of students already described in a quantitative course and a qualitative course. The data was obtained from institutional records of the University of Colorado-Boulder's Undergraduate EM Program. The data accounts for five terms, between Spring 2015 and Fall 2016 of two undergraduate EM courses. The quantitative course was entitled: Engineering Economics and the qualitative course was called: Leadership and Professional Development. From this point on, the former course will be referred to as "Engineering Econ" and the latter group as: "Leadership". The following paragraphs contains a brief description of each course and the learning outcomes considered.

\section{Courses and learning outcomes description}

Engineering Econ: The Engineering Econ course has been taught by the same instructor across the three course modalities previously described. During the Spring 2015 term, the course was taught in the traditional setting with in-class students only. From Summer 2015 to Spring 2016 (three terms) this course was taught in the blended modality with face-to-face students in class, and distance students who watched recordings of the class. Lastly, during Summer 2016 the class transitioned to a completely online setting where all students participated online by watching instructional videos developed by the instructor not in a classroom setting. The curriculum was 
specifically developed to support an online learning environment. The instructor designed the online course using numerous, short videos explaining individual concepts within the curriculum. Students could watch the short videos from the learning management system when they needed additional instruction on a challenging concept.

The class included homework (HW) assignments, tests, and participation activities. Grading of HW assignments and tests was completely objective and carried out by a software based on specific numerical answers incorporated in the software. Furthermore, the selection of HW assignments for each term remained consistent throughout the study period. Tests were administered two times during the term in the form of midterm and final exams, and their grading was also done by the publisher provided software. The assessment of participation varied depending on the course modality and type of student. Participation of traditional students was determined by their attendance and contribution in class discussion and group exercises. For faceto-face students, participation was based on their attendance, in-class contributions and their input to already created online threaded discussions. Distance students and online students participated by creating new online threaded discussions and by posting comments on existing discussions. For this study, the primary learning outcomes considered were the overall $\mathrm{HW}$ grades, test grades and participation grades of each student.

Leadership: This qualitative course was taught in the first two modalities: traditional and blended, but not in the online modality. Throughout the period considered in this study, the same professor taught the class and graded the students. The Leadership course was also taught in the traditional modality during the Spring 2015 term. The other four terms considered were taught in the blended modality with face-to-face and distance students.

Likewise, the learning outcomes considered for this course consisted of overall HW grades, test grades, and participation grades. Homework assignments involved keeping a journal and participating in specific practical activities outside the classroom. Tests were administered in essay format, which fulfilled the function of midterm exams. Finally, participation was determined following the procedure described in the previous section for face-to-face and distance students. Given these characteristics, the researchers feel confident making comparisons between these two types of courses and conclude that the study has good internal validity.

\section{Objective learning outcomes: HW grades, participation grades, and test grades}

Faculty Course Questionnaires (FCQ): The FCQ is a tool to evaluate the students' perception of the benefits of the course and the quality of the professor. In compliance with the University of Colorado Board of Regents Policy 4-B, this voluntary questionnaire is administered to the students in each class at the end of the term. The questionnaire consists of a series of questions and affirmations that students can answer or indicate the degree to which they agree with the affirmation by selecting a value in a 6 point Likert-type scale. Eight of these items were selected to evaluate subjective learning outcomes associated with each of the student types. The following list includes the selected items: 
FCQ selected items:

1) Hours per week spent on course, including class time (i1)

2) Intellectual challenge of the course (i2)

3) How much you learned in this course (i3)

4) Course overall (i4)

5) Instructor overall (i5)

6) This class improved my understanding of the profession I plan to practice. (i6)

7) My confidence to succeed as a student was enhanced. (i7)

8) This course prepared me for my chosen career. (i8)

Subjective learning outcomes: $i 1, i 2, i 3, i 4, i 5, i 6, i 7, i 8$

Sample: The sample consisted of 390 undergraduate students from the University of ColoradoBoulder. Demographics regarding gender and age were banned from the raw data and for that reason they are not presented in this study. In line with the objectives of this study, the participants were classified per student types already described. Table 2 summarizes sample sizes by type of course and student.

Table 2: Type of Students and Sample Size by Course

\begin{tabular}{llll}
\hline \multicolumn{2}{l}{ Quantitative course: } & Eng. Econ & \multicolumn{2}{l}{ Qualitative course: } & Leadership \\
\hline Traditional & $\mathrm{n}=30$ & Traditional & $\mathrm{n}=44$ \\
Face-to-Face & $\mathrm{n}=101$ & Face-to-Face & $\mathrm{n}=96$ \\
Distance & $\mathrm{n}=53$ & Distance & $\mathrm{n}=32$ \\
Online & $\mathrm{n}=34$ & & \\
\hline
\end{tabular}

Statistical analysis

Statistical procedures: To give an answer to each of the research questions the researchers need to test the alternative hypothesis that the learning outcomes means are different when comparing across student types. These hypotheses can most properly be tested by performing an analysis of variance (ANOVA). Objective learning outcomes can be considered as continuous ratio data. However, given the fact that each of these variables showed to be highly not normal, they were treated as nominal data. Subjective learning outcomes are, by nature, nominal data. Consequently, all the data analyzed in this study were considered as nominal and all statistical procedures were chosen accordingly.

Given the non-parametric character of the data, a One-way ANOVA on Ranks was performed. This test is most commonly known as the Kruskal-Wallis test by ranks, which does not assume normally distributed data, and states as alternative hypothesis that the population mean rank of at least one group is different from the population mean rank of at least one other group (Kruskal \& Wallis, 1952). The test can determine a significant difference between three or more groups but it is not able to assess the significance of difference in medians between two groups. For this purpose, the Wilcoxon-Mann-Whitney test was also performed. 
Statistical models' assumptions: These two models are based on three fundamental assumptions. The first assumption is that the variables should be ordinal or continuous. Given the characteristics of the data this assumption is met. The second assumption is that the independent variables are independent from one another. In this case, HW assessment does not affect participation or test grades. This same reasoning can be applied to the different combinations between these variables and also to the subjective learning outcomes. Therefore, these variables meet the second assumption. The third assumption states that there must be independence within groups of variables. In this case, the grades of one student doesn't affect the grades of another student. Additionally, because FCQ's are completed individually this assumption is also met by the subjective learning outcomes. Lastly, an additional fourth assumption assumes equal distribution shape across the independent variables. This is not the case in the data and for that reason conclusions from differences in mean ranks can be determined but not for differences in medians.

Having tested the assumptions of the statistical models applied it is possible now to proceed with the interpretation of the results. The following section presents the results obtained organized by class type.

Results

\section{Results obtained from the Engineering Econ class}

To interpret the significance of the results, the researchers have chosen a significance level of $95 \%$. This translates to an alpha equal to 0.05 for Kruskal-Wallis test and an alpha of 0.0083 for Wilcoxon-Mann-Whitney test after applying Bonferroni correction for multiple tests. All statistical analyses were performed in MVPstats version 2012/09/06.

Difference between student types considering objective learning outcomes: The results from the Kruskal-Wallis test in HW grades across the four types of students revealed significant differences. Consequently, a Wilcoxon-Mann-Whitney test was performed between each pair of variables (6 tests) and the results indicated that the mean rank of traditional students' HW grades was significantly different from all other groups. Table 3 summarizes these results.

Table 3: Differences in HW Grades Across Student Types

\begin{tabular}{lllll}
\hline Kruskal-Wallis & $\mathrm{H}=33.5$ & $\mathrm{p}$-value: $0.000^{*}$ & Wilcoxon-Mann-Whitney test (p-value) \\
\hline Student Type & Mean Rank & & & \\
\hline Traditional & 51.5 & & & \\
Face-to-face & 117.4 & $1 \mathrm{vs} 2(0.000)^{*}$ & & \\
Distance & 109.5 & $1 \mathrm{vs} 3(0.000)^{*}$ & $2 \mathrm{vs} 3(0.412)$ & \\
Online & 137.3 & $1 \mathrm{vs} 4(0.000)^{*}$ & $2 \mathrm{vs} 4(0.105)$ & 3vs4(0.048) \\
\hline
\end{tabular}

*Statistically significant

When comparing test grades and participation grades across student types, no significant difference was found. Table 4 summarizes these results. 
Table 4: Differences in Test and Participation Grades Across Student Types

\begin{tabular}{lll}
\hline \multirow{2}{*}{ Kruskal-Wallis test } & Test & Participation \\
& H=2.5 p-value: 0.479 & H=6.4 p-value: 0.092 \\
\hline Student Type & Mean Rank & Mean Rank \\
\hline Traditional & 103.8 & 120.6 \\
Face-to-face & 113.4 & 101.1 \\
Distance & 112.2 & 106.4 \\
Online & 95.2 & 129.4 \\
\hline
\end{tabular}

Differences between student types considering subjective learning outcomes: After comparing subjective learning outcomes across the four student types only one variable showed to be significant. The significant variable was "Intellectual challenge of the course" (i2) and the results are presented in Table 5.

Table 5: Differences in i2 Answer Across Student Types

\begin{tabular}{lllll}
\hline Kruskal-Wallis & $\mathrm{H}=10.3$ & $\mathrm{p}$-value: $0.016^{*}$ & Wilcoxon-Mann-Whitney test (p-value) \\
\hline Student Type & Mean Rank & & & \\
\hline Traditional & 44.4 & & & \\
Face-to-face & 52.4 & $1 \mathrm{vs} 2(0.389)$ & & \\
Distance & 73.7 & $1 \mathrm{vs} 3(0.009)$ & $2 \mathrm{vs} 3(0.005)^{*}$ & \\
Online & 48.5 & $1 \mathrm{vs} 4(0.691)$ & $2 \mathrm{vs} 4(0.674)$ & $3 \mathrm{vs} 4(0.023)$ \\
\hline
\end{tabular}

*Statistically significant

\section{Results obtained from the Leadership class}

In this case alpha for Kruskal-Wallis testing is still 0.05. However, significance for the WilcoxonMann-Whitney test will be determined by an alpha equal to 0.017 per Bonferroni correction for three tests.

Differences between student types considering objective learning outcomes: Kruskal-Wallis testing revealed that there is a significant difference regarding test grades across the student types, these results can be seen in Table 6. The other two variables didn't show a significant difference as illustrated in Table 7.

Table 6: Differences in Test Grades Across Student Types

\begin{tabular}{llll}
\hline Kruskal-Wallis & $\mathrm{H}=15.4$ & $\mathrm{p}$-value: $0.000 *$ & Wilcoxon-Mann-Whitney (p-value) \\
\hline Student Type & Mean Rank & & \\
\hline Traditional & 61.4 & & \\
Face-to-face & 93.8 & $1 \mathrm{vs} 2(0.000)^{*}$ & \\
Distance & 99.2 & $1 \mathrm{vs} 3(0.001)^{*}$ & $2 \mathrm{vs} 3(0.579)$ \\
\hline *Statistically significant & &
\end{tabular}

*Statistically significant 
Table 7: Differences in HW and Participation Grades Across Student Types

\begin{tabular}{lll}
\hline \multirow{2}{*}{ Kruskal-Wallis test } & HW & Participation \\
& H=0.177 p-value: 0.915 & H=2.25 p-value: 0.325 \\
\hline Student Type & Mean Rank & Mean Rank \\
\hline Traditional & 84.1 & 60.3 \\
Face-to-face & 86.8 & 68.5 \\
Distance & 88.8 & 56.2 \\
\hline
\end{tabular}

Differences between student types considering subjective learning outcomes: Two subjective learning outcomes were found to be significant: "Course overall" (i4) and "This course prepared me for my chosen career" (i8). These results can be seen in in Table 8 and Table 9 respectively.

Table 8: Differences i4 Across Student Types

\begin{tabular}{llll}
\hline Kruskal-Wallis & $\mathrm{H}=7.8 \quad$ p-value: $0.020^{*}$ & Wilcoxon-Mann-Whitney (p-value) \\
\hline Student Type & Mean Rank & & \\
\hline Traditional & 41.9 & & \\
Face-to-face & 49.8 & $1 \mathrm{vs} 2(0.196)$ & \\
Distance & 29.9 & $1 \mathrm{vs} 3(0.187)$ & $2 \mathrm{vs} 3(0.005)^{*}$ \\
\hline
\end{tabular}

*Statistically significant

Table 9: Differences i8 Across Student Types

\begin{tabular}{llll}
\hline Kruskal-Wallis & $\mathrm{H}=7.6 \quad \mathrm{p}$-value: $0.022 *$ & Wilcoxon-Mann-Whitney (p-value) \\
\hline Student Type & Mean Rank & & \\
\hline Traditional & 39.4 & & \\
Face-to-face & 49.2 & $1 \mathrm{vs} 2(0.101)$ & \\
Distance & 30.4 & $1 \mathrm{vs} 3(0.275)$ & $2 \mathrm{vs} 3(0.009) *$ \\
\hline
\end{tabular}

*Statistically significant

Analysis

Engineering Econ: The study of differences regarding objective learning outcomes across the four student types considered in this study indicated that HW grades of traditional students are significantly lower than those obtained by any other student type. Further, the greatest difference was found between traditional students and online students, in which online students showed a mean rank 2.7 times greater than traditional students.

When testing for differences in subjective learning outcomes across the different student types, there was a significant difference between the two types of students in a blended course. Distance students found the course to be more challenging than face-to-face students as indicated by a mean rank 1.4 times greater.

Leadership: The analysis of objective learning outcomes indicated that face-to-face and distance students performed much better than traditional students on their exams, presenting a tests' mean 
rank approximately $50 \%$ higher than that of traditional students. Additionally, the study of subjective learning outcomes indicated that distance students not only evaluated the overall course much lower, but they also felt that the course was less useful for their professional development when compared to face-to-face students in a blended course.

\section{Limitations}

There are several limitations associated with this research work. For example, the data belongs to the same EM program at the University of Colorado-Boulder. Thus, the obtained data are narrow and this could have conditioned the results. Additionally, these classes were elective rather than required and the results of these analyses could potentially vary from those obtained from students that attended required classes.

\section{Discussion}

Before, there was no empirical evidence of the differences in learning outcomes and engagement across these types of students attending undergraduate EM programs. This study has exposed the advantages and disadvantages associated with each of these groups, thus underlying the differences between the three course modalities presented (traditional, blended, and online).

The current paper demonstrates that some objective learning outcomes such as HW and test grades may improve from a traditional course to a blended course, and from a blended course to an online course. However, no significant differences were found in regards to participation. It is possible to conclude that there is an improvement in some learning outcomes when transitioning from a traditional course to a blended course to an online course. Regarding student engagement, no definitive statement can be made from the results. The improvement in HW grades indicates that students from blended courses and online courses invested more time and effort in this activity when compared to traditional students. However, the lack of a significant difference in participation between these groups doesn't allow the authors to make a conclusive statement regarding engagement. These results will encourage the continuity of adaptation of course programs from a traditional setting to a blended or online setting in undergraduate EM programs.

Another interesting and important result of this study is that distance students from a blended course are not as satisfied with the course as are face-to-face students in the same modality. Additionally, they find the course more challenging and less useful to their development as professionals compared to face-to-face students. This may be attributed to the fact that in a blended course of these characteristics, students in the classroom drive the professor's attention almost exclusively to them rather than to those who will watch the class afterwards. Consequently, the professor focuses almost exclusively on in-class students and distance students become an afterthought. Thus, distance students' may feel their needs are not fully met and interaction between the professor and those students is lower. The interaction between students may also suffer. All these factors combine to give a lower learning quality experience to distance students in blended courses. While the students in the blended course watch a pre-recorded classroom instructor teaching to both a camera and a group of in-class students, a completely online modality is specifically designed for the online learner. The online group showed a positive attitude towards their instructor and engagement in the course. As mentioned, online students are able to go directly 
to the learning management system and view short videos while the distance students in the blended modality would have to view an hour and a half lecture to "hunt" for the instructor's explanation about a particular concept, thus treating the distance student as if they were in the classroom.

These findings can help institutions to make decisions regarding what class modality to implement in undergraduate EM programs. Additionally, these results may drive educators to make adjustments to blended courses to offer a better experience for distance students. Lastly, the way in which the data was collected, considering students from a qualitative and a quantitative course, established external validity of the results under similar conditions. To generalize the results, future research could investigate learning outcomes and engagement across EM undergraduate programs from different institutions.

\section{References}

ASEM. (2017). "Engineering Mgmt. Programs | ASEM World Headquarters." <https://www.asem.org/EM-Program-List> (Feb. 11, 2017).

Astin, A. W. (1984). Student involvement: A developmental theory for higher education. Journal of College Student Personnel, 25(4), 297-308.

Banathy, B. (1994). Designing educational systems: Creating our future in a changing world. Systemic Change in Education, 27-34.

Barr, R. B., and Tagg, J. (1995). From teaching to learning — A new paradigm for undergraduate education." Change: The Magazine of Higher Learning, 27(6), 12-26.

Brown, R. E. (2001). The process of community-building in distance learning classes. Journal of Asynchronous Learning Networks, 5(2), 18-35.

Bullen, M. (2007). Participation and critical thinking in online university distance education. International Journal of E-Learning \& Distance Education, 13(2), 1-32.

Candy, P. C., Crebert, G., and O'leary, J. (1994). Developing lifelong learners through undergraduate education. AGPS Canberra.

Carini, R. M., Kuh, G. D., and Klein, S. P. (2006). Student engagement and student learning: Testing the linkages. Research in Higher Education, 47(1), 1-32.

Collins, M. (2000). Comparing Web, Correspondence and Lecture versions of a second-year non-major Biology course. British Journal of Educational Technology, 31(1), 21-27.

Crome, K., Farrar, R., and O'Connor, P. (2009). What is autonomous learning? Discourse, 9(1), 111-126.

Cross, K. P. (1999). Assessment to improve college instruction. Assessment in Higher Education: Issues of Access, Quality, Student Development, and Public Policy, 35-46.

Dearing, R. (1997). The Dearing Report. The National Committee of Enquiry into Higher Education.

Edwards, M. E., Cordray, S., and Dorbolo, J. (2000). Unintended benefits of distance-education technology for traditional classroom teaching. Teaching Sociology, 28(4), 386-391.

Ewell, P. T., and Jones, D. P. (1996). Indicators of "good practice" in undergraduate education: A handbook for development and implementation. ERIC Clearinghouse.

Fishman, B. J. (1999). Characteristics of students related to computer-mediated communications activity. Journal of Research on Computing in Education, 32(1), 7397. 
Fredericksen, E., Pickett, A., Shea, P., Pelz, W., and Swan, K. (2000). Student satisfaction and perceived learning with on-line courses: Principles and examples from the SUNY learning network. Journal of Asynchronous Learning Networks, 4(2), 7-41.

Fries-Britt, S. (2000). Identity development of high-ability black collegians. New Directions for Teaching and Learning, 2000(82), 55-65.

Handelsman, M. M., Briggs, W. L., Sullivan, N., and Towler, A. (2005). A Measure of College Student Course Engagement. The Journal of Educational Research, 98(3), 184-192.

Hannum, W. H., and Briggs, L. J. (1982). How does instructional systems design differ from traditional instruction? Educational Technology, 22(1), 9-14.

Hill, J. R. (1997). Distance learning environments via the World Wide Web. Web-based Instruction, 75-80.

Johnson, S. D., Aragon, S. R., Shaik, N., and Palma-Rivas, N. (2000). Comparative analysis of learner satisfaction and learning outcomes in online and face-to-face learning environments." Journal of Interactive Learning Research; Charlottesville, 11(1), 29-49.

Karabulut-Ilgu, A., and Jahren, C. (2016). Evaluation of hybrid learning in a construction engineering context: A mixed-method approach." Advances in Engineering Education, $5(3)$.

Kotnour, T., and Farr, J. V. (2005). Engineering Management: Past, present, and future. Engineering Management Journal, 17(1), 15-26.

Kruskal, W. H., and Wallis, W. A. (1952). "Use of ranks in one-criterion variance analysis." Journal of the American statistical Association, 47(260), 583-621.

Kuh, G. D., Kinzie, J., Buckley, J. A., Bridges, B. K., and Hayek, J. C. (2011). Piecing Together the Student Success Puzzle: Research, Propositions, and Recommendations: ASHE Higher Education Report. John Wiley \& Sons.

Kulik, C.-L. C., and Kulik, J. A. (1991). Effectiveness of computer-based instruction: An updated analysis. Computers in Human Behavior, 7(1), 75-94.

Lamport, M. A., and Hill, R. J. (2012). Impact of hybrid instruction on student achievement in post-secondary institutions: A synthetic review of the literature. Journal of Instructional Research, 1(1), 49-54.

Leasure, A. R., Davis, L., and Thievon, S. L. (2000). Comparison of student outcomes and preferences in a traditional vs. world wide web-based baccalaureate nursing research course. Journal of Nursing Education, 39(4), 149-154.

Little, D. (1996). Freedom to learn and compulsion to interact: Promoting learner autonomy through the use of information systems and information technologies. Taking Control: Autonomy in Language Learning, 203-218.

Maeroff, G. (2003). A classroom of one: How online education is changing our schools and colleges. New York: Palgrave Macmillian.

Means, B. (2009). Evaluation of Evidence-Based Practices in Online Learning: A Meta-Analysis and Review of Online Learning Studies. US Department of Education.

Meyer, K. A. (2003). Face-to-face versus threaded discussions: The role of time and higherorder thinking. Journal of Asynchronous Learning Networks, 7(3), 55-65.

Meyer-Peyton, L. (1999). Elements of a successful distributed learning program. Distance Learning Technologies: Issues, Trends and Opportunities, 82.

Murray, S. L., and Raper, S. A. (1997). Engineering management and industrial engineering: Six one way, a half dozen the other.

Newman, D. R., Webb, B., and Cochrane, C. (1995). A content analysis method to measure 
critical thinking in face-to-face and computer supported group learning. Interpersonal Computing and Technology, 3(2), 56-77.

Oliver, R., and Omari, A. (2001). Student responses to collaborating and learning in a webbased environment. Journal of Computer Assisted Learning, 17(1), 34-47.

Purcell-Robertson, R. M., and Purcell Sr, D. F. (1999). Interactive distance learning. Distance Learning Technologies: Issues, Trends and Opportunities, 16.

Rabe-Hemp, C., Woollen, S., and Humiston, G. S. (2010). "A comparative analysis of student engagement, learning, and satisfaction in lecture hall and online learning settings. Quarterly Review of Distance Education, Volume 10 Book 2009, 10(2), 207.

Reay, J. (2001). Blended learning-a fusion for the future. Knowledge Management Review, 4(3), 6 .

Santiago, L., and Abioye, O. L. (2014). "e-Learning: Teaching Computer Programming Online to First-Year Engineering Students.” 24.445.1-24.445.8.

Schwitzer, A. M., and Lovell, C. (1999). Effects of goal instability, peer affiliation, and teacher support on distance learners. Journal of College Student Development, 40(1), 43.

Webster, J., and Hackley, P. (1997). Teaching effectiveness in technology-mediated distance learning. Academy of Management Journal, 40(6), 1282-1309.

Weimer, M. (2002). Learner-Centered teaching: Five key changes to practice. John Wiley \& Sons. 